\title{
Development and Validation of Stability-Indicating HPTLC Determination of Tamsulosin in Bulk and Pharmaceutical Dosage Form
}

\author{
S. B. Bari, A. R. Bakhshi, P. S. Jain, and S. J. Surana \\ R. C. Patel Institute of Pharmaceutical Education and Research (RCPIPER), Shirpur, District Dhule, Maharashtra 425 405, India
}

Correspondence should be addressed to P. S. Jain, pritash79@yahoo.com

Received 14 October 2010; Accepted 20 December 2010

Academic Editor: Cristina Minguillón

Copyright ( 2011 S. B. Bari et al. This is an open access article distributed under the Creative Commons Attribution License, which permits unrestricted use, distribution, and reproduction in any medium, provided the original work is properly cited.

\begin{abstract}
A simple, economic, selective, precise, and stability-indicating high-performance thin-layer chromatographic method for analysis of tamsulosin hydrochloride, both as a bulk drug and in formulations, was developed and validated according to ICH guidelines. The method employed HPTLC aluminium plates precoated with silica gel 60F-254 as the stationary phase while the solvent system consisted of toluene : methanol : triethylamine $(3.5: 1.2: 0.2 \mathrm{v} / \mathrm{v})$. The system was found to give compact spot for drug $\left(R_{f}\right.$ value of $0.52 \pm 0.02$ ). Densitometric analysis of tamsulosin was carried out in the absorbance mode at $280 \mathrm{~nm}$. The linear regression analysis data for the calibration plots showed good linear relationship, $r^{2}=0.9982 \pm 0.0012$, with respect to peak area in the concentration range 400-2400 ng per spot. The mean value \pm SD of slope and intercept were $2.6553 \pm 0.0173$ and $777.7 \pm 74.8$ with respect to peak area. The method was validated for precision, recovery, and robustness. The limits of detection and quantitation were 20.49 and $62.10 \mathrm{ng}$ per spot, respectively. Tamsulosin was subjected to hydrolysis, oxidation, and thermal degradation which indicate the drug is susceptible to hydrolysis, oxidation, and heat. Statistical analysis proves that the method is repeatable, selective, and accurate for the estimation of tamsulosin.
\end{abstract}

\section{Introduction}

Benign prostate hyperplasia (BPH) is a common condition in ageing men. Chemically, tamsulosin hydrochloride is $[(-)-$ (R)-5-[2-[[2-(O-ethoxyphenoxy)ethyl]amino]propyl]-2-methoxybenzenesulfonamide] and is official in MartindaleThe Extra Pharmacopoeia and Merck Index [1, 2]. Tamsulosin hydrochloride exists in two enantiomeric forms, but only R-isomer is the pharmaceutically active component. It is a new type of highly selective $\alpha$-1-adrenergic receptor antagonist for treatment of $\mathrm{BPH}$. Compared to other $\alpha$-antagonists, tamsulosin hydrochloride has greater specificity for $\alpha-1$ receptors in the human prostate and does not affect receptors on blood vessels. It is the most frequently prescribed medication for the treatment of lower urinary tract symptoms. It is a white to yellowish-white powder, slightly soluble in water, soluble in methanol, and chloroform-administered orally. Literature survey reveals the chiral separation by electrophoresis [3, 4], UV [5], and HPLC methods [6-8], coupled with ESI-MS-MS are reported for the estimation of tamsulosin hydrochloride with its impurities in bulk and pharmaceutical formulations [9] as well as in biological fluids [10-17]. The present work deals with HPTLC stability for tamsulosin hydrochloride in bulk and pharmaceutical formulation which is economical and intended for better reproducibility of degraded products, and this work is genuine as it is not used by any other author.

\section{Experimental}

2.1. Materials. Tamsulosin hydrochloride was kindly gifted from Sun Pharmaceuticals, Vapi (Gujarat, India). All chemicals and reagents used were of analytical grade and purchased from Merck fine chemicals, Mumbai (Maharashtra, India).

2.2. HPTLC Instrumentation. The samples were spotted in the form of bands of width $6 \mathrm{~mm}$ with a Camag 100 microlitre sample syringe (Hamilton, Bonaduz, Switzerland) 
using Camag Linomat 5 (Switzerland) sample applicator on precoated silica gel aluminium plate $60 \mathrm{~F}-254(10 \mathrm{~cm} \times$ $10 \mathrm{~cm}$ with $0.2 \mathrm{~mm}$ thickness, E. Merck, Germany). A constant application rate of $200 \mathrm{~nL} / \mathrm{s}$ was employed, and space between two bands was $8 \mathrm{~mm}$. The slit dimension was kept $5 \mathrm{~mm} \times 0.45 \mathrm{~mm}$ micro and $20-\mathrm{mm} / \mathrm{s}$ scanning speed was employed. The mobile phase consisted of toluene: methanol: triethylamine $(3.5: 1.2: 0.2 \mathrm{v} / \mathrm{v})$. Linear ascending development was carried out in twin trough glass chamber saturated with mobile phase. The optimized chamber saturation time for mobile phase was $20 \mathrm{~min}$ at room temperature. The length of chromatogram run was approximately $80 \mathrm{~mm}$. Subsequent to the development, TLC plate was dried in a current of air with the help of an air dryer. Densitometric scanning was performed on Camag TLC scanner 3 in the absorbance mode at $280 \mathrm{~nm}$. The source of radiation was deuterium lamp.

\subsection{Method Validation}

2.3.1. Calibration Curve of Tamsulosin Hydrochloride. A stock solution of tamsulosin hydrochloride $(1000 \mu \mathrm{g} / \mathrm{mL})$ was prepared in methanol. From stock solution, a solutions of $400 \mu \mathrm{g} / \mathrm{mL}$ was prepared. The solution was then spotted in three replicate on TLC plate to obtain concentration of 400, $800,1200,1600,2000$, and $2400 \mathrm{ng}$ per spot of tamsulosin hydrochloride, respectively. The data of peak area versus drug concentration were treated by linear least square regression.

2.3.2. Precision. Repeatability of sample application and measurement of peak area were carried out using six replicates of the same spot ( $800 \mathrm{ng}$ per spot of tamsulosin hydrochloride). The intraday and interday variation for the determination of tamsulosin hydrochloride was carried out at three different concentration levels of 800,1200 , and 1600 ng per spot.

2.3.3. Robustness of the Method. By introducing small changes in the mobile phase composition, the effects on the results were examined. Mobile phases having different composition of toluene: methanol:triethylamine (3.5:1.2:0.2 and $3: 1.2: 0.2 \mathrm{v} / \mathrm{v})$ were tried and chromatograms were run. The amount of mobile phase, temperature, and relative humidity was varied in the range of $\pm 5 \%$. The plates were prewashed by methanol and activated at $60 \pm 5^{\circ} \mathrm{C}$ for 2,5 , and $7 \mathrm{~min}$ prior to chromatography. Time from spotting to chromatography and from chromatography to scanning was varied from $0,20,40$, and $60 \mathrm{~min}$. Robustness of the method was done at three different concentration levels: 800, 1200, and $1600 \mathrm{ng}$ per spot.

2.3.4. Limit of Detection and Limit of Quantification. In order to determine detection and quantification limit, tamsulosin hydrochloride concentrations in the lower part of the linear range of the calibration curve were used. Tamsulosin hydrochloride solution of $200 \mu \mathrm{g} / \mathrm{mL}$ was prepared and 400 , $500,600,700$, and $800 \mathrm{ng} / \mu \mathrm{L}$ was applied in triplicate. The amount of tamsulosin hydrochloride by spot versus
TABLE 1: Summary of validation parameters.

\begin{tabular}{lc}
\hline Parameter & Data \\
\hline Linearity range (ng per spot) & $400-2400$ \\
Correlation coefficient & 0.9982 \\
Limit of detection (ng per spot) & 20.49 \\
Limit of quantitation (ng per spot) & 62.10 \\
Recovery $(n=6)$ & 100.74 \\
Precision (\% R.S.D.) & \\
Repeatability of application $(n=6)$ & 1.43 \\
Repeatability of measurement $(n=6)$ & \\
Interday $(n=6)$ & 1.45 \\
Intraday $(n=6)$ & 0.87 \\
Robustness & 1.05 \\
Specificity & specific \\
\hline
\end{tabular}

average response (peak area) was graphed, and the equation for this was determined. The standard deviations (SD) of responses were calculated. The average of standard deviations was calculated (A.S.D.). Detection limit was calculated by $(3.3 \times$ A.S.D. $) / b$, and quantification limit was calculated by $(10 \times$ A.S.D. $) / b$, where " $b$ " corresponds to the slope obtained in the linearity study of method.

2.3.5. Specificity. The specificity of the method was ascertained by analyzing standard drug and sample. The spot for tamsulosin hydrochloride in sample was confirmed by comparing the $R_{f}$ values and spectra of the spot with that of standard. The peak purity of tamsulosin hydrochloride was assessed by comparing the spectra at three different levels, that is, peak start $(S)$, peak apex $(M)$, and peak end $(E)$ positions of the spot.

2.3.6. Recovery Studies. The analyzed samples were spiked with extra 80,100 , and $120 \%$ of the standard tamsulosin hydrochloride, and the mixture was analyzed by the proposed method. At each level of the amount, six determinations were performed. This was done to check the recovery of the drug at different levels in the formulations (Table 4).

2.4. Analysis of Tamsulosin Hydrochloride in Prepared Formulation. To determine the concentration of tamsulosin hydrochloride in tablets (labeled claim: $0.4 \mathrm{mg}$ per tablet), the contents of 25 tablets were weighed, their mean weight determined, and they were finely powdered. The powder equivalent to $10 \mathrm{mg}$ of tamsulosin hydrochloride was weighed. The drug from the powder was extracted with methanol. To ensure complete extraction of the drug, it was sonicated for $30 \mathrm{~min}$, and the volume was made up to $10.0 \mathrm{~mL}$. The resulting solution was centrifuged at $3000 \mathrm{rpm}$ for $5 \mathrm{~min}$, and supernatant was analyzed for drug content. The $4 \mathrm{~mL}$ was taken and volume made up to $10.0 \mathrm{~mL}$ by methanol, to make a $400-\mu \mathrm{g} / \mathrm{mL}$ solution. The above solution (800 ng per spot) was applied on TLC plate followed by development and scanning as described in Section 2.2. 
The analysis was repeated in triplicate. The possibility of excipient interferences in the analysis was studied.

\subsection{Forced Degradation of Tamsulosin Hydrochloride}

2.5.1. Hydrogen Peroxide-Induced Degradation. The $10 \mathrm{mg}$ of tamsulosin hydrochloride was separately dissolved in methanolic solution of hydrogen peroxide $(30.0 \%, \mathrm{v} / \mathrm{v})$. The solution was kept for " $16 \mathrm{~h}$ " at room temperature in the dark in order to exclude the possible degradative effect of light. The $4.0 \mathrm{~mL}$ of the above solution was taken and diluted up to $10.0 \mathrm{~mL}$ with methanol. The resultant solution was applied on TLC plate in triplicate (3.0 $\mu \mathrm{L}$ each, i.e., $1200 \mathrm{ng}$ per spot). The chromatograms were run as described in Section 2.2.

2.5.2. Dry Heat Degradation Product. The powdered drug was stored at $60^{\circ} \mathrm{C}$ for " $2 \mathrm{~h}$ " under dry heat condition showed significant degradation. The degraded products were resolved from the standard. In all degradation studies, the average peak areas of tamsulosin hydrochloride after application was $1200 \mathrm{ng}$ per spot of three replicates.

2.5.3. Acid and Alkaline Hydrolysis. Tamsulosin hydrochloride $(10 \mathrm{mg})$ was separately dissolved in $10 \mathrm{~mL}$ methanolic solution of $2 \mathrm{M} \mathrm{HCl}$ and $2 \mathrm{M} \mathrm{NaOH}$. This solution was kept for " $6 \mathrm{~h}$ " at room temperature in the dark in order to exclude the possible degradative effect of light. Further, it was refluxed for " $1 \mathrm{~h}$ " at $55^{\circ} \mathrm{C}$. The $4 \mathrm{~mL}$ of the above solution was taken and neutralized, then diluted up to $10 \mathrm{~mL}$ with methanol. The resultant solution was applied on TLC plates in triplicates ( $3 \mu \mathrm{L}$ each, i.e., $1200 \mathrm{ng}$ per spot). The chromatograms were run as described in Section 2.2.

2.5.4. Light Heat Degradation Products. Tamsulosin hydrochloride $(10 \mathrm{mg})$ was dissolved in $10 \mathrm{~mL}$ of methanol. The solution was kept in the sun light for " $24 \mathrm{~h}$ ". $4 \mathrm{~mL}$ of the above solution were taken and diluted up to $10 \mathrm{~mL}$ with methanol (Figure 6). The resultant solution was applied on TLC plate in triplicate ( $3 \mu \mathrm{L}$ each, i.e., $1200 \mathrm{ng}$ per spot). The chromatograms were run as described in Section 2.2.

\section{Results and Discussion}

3.1. Development of Optimum Mobile Phase. TLC procedure was optimized with a view to developing a stability-indicating assay method. Initially, toluene: 1 -propanol $(3: 2 \mathrm{v} / \mathrm{v})$ was tried with good resolution with an $R_{f}$ value of 0.3 for tamsulosin hydrochloride, but typical peak nature was missing; moreover, it was felt necessary to increase the $R_{f}$ for better resolution of impurities. Finally, the mobile phase consisting of toluene:methanol:triethylamine $(3.5: 1.2: 0.2 \mathrm{v} / \mathrm{v})$ gave a sharp and well-defined peak at an $R_{f}$ value of 0.52 (Figure 1). Well-defined spots were obtained when the chamber was saturated with the mobile phase for $20 \mathrm{~min}$ at room temperature.

3.2. Calibration Curves. The linear regression data for the calibration curves $(n=3)$, as shown in Table 1, showed

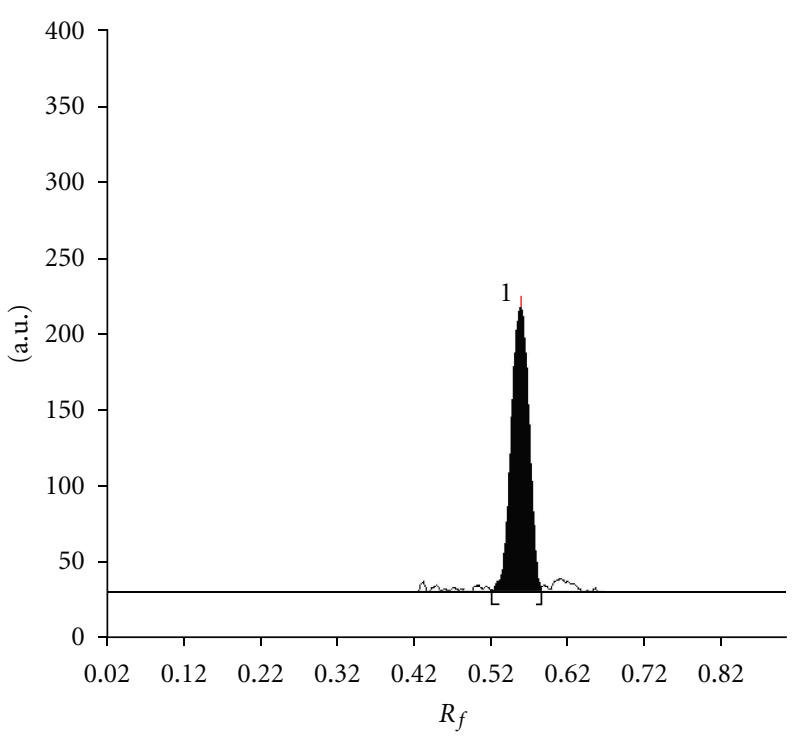

FIGURE 1: A typical HPTLC densitogram of tamsulosin hydrochloride $\left(R_{f}=0.52\right)$ in toluene : methanol : triethylamine (3.5: $1.2: 0.2$, $\mathrm{v} / \mathrm{v})$ at $280 \mathrm{~nm}$.

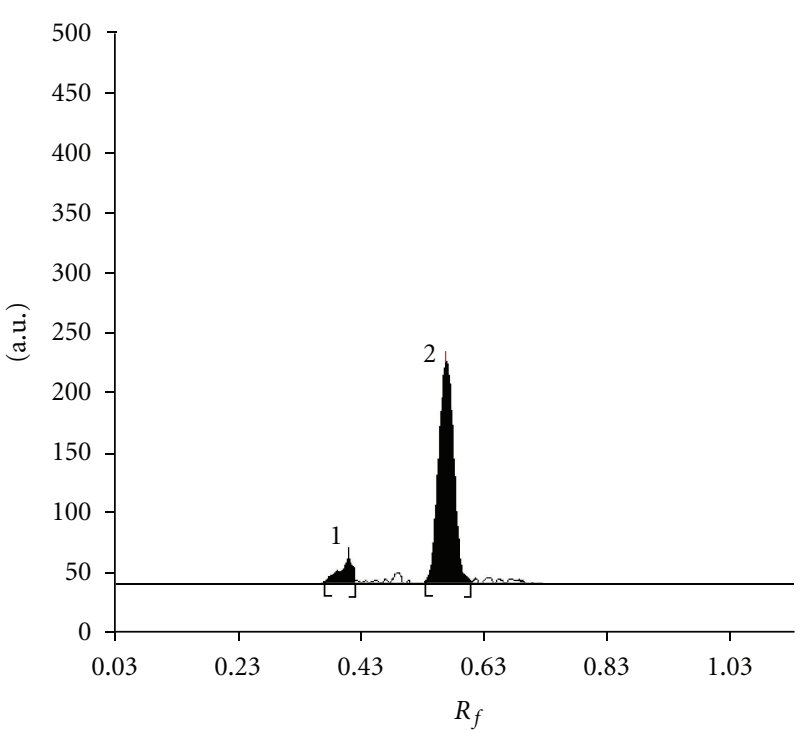

FIGURE 2: HPTLC densitogram of tamsulosin hydrochloride after treatment with $30 \%$ hydrogen peroxide for " $16 \mathrm{~h}$ ".

a good linear relationship over the concentration range 400$2400 \mathrm{ng}$ per spot with respect to peak area. No significant difference was observed in the slopes of standard curves (ANOVA, $P>.05$ ).

\subsection{Validation of the Method}

3.3.1. Precision. The repeatability of sample application and measurement of peak area were expressed in the terms of $\%$ R.S.D. and results are depicted in Table 2, which revealed intraday and interday variation of tamsulosin hydrochloride 
TABLE 2: Intraday and interday precision of HPTLC method ${ }^{\mathrm{a}}$.

\begin{tabular}{|c|c|c|c|c|c|c|c|c|}
\hline \multirow[t]{2}{*}{ Amount (ng per spot) } & \multicolumn{4}{|c|}{ Intraday precision } & \multicolumn{4}{|c|}{ Interday precision } \\
\hline & Mean area & $\mathrm{SD}$ & \% R.S.D. & S.E. ${ }^{b}$ & Mean area & $\mathrm{SD}$ & \% R.S.D. & S.E. ${ }^{b}$ \\
\hline 800 & 2974.6 & 15.00 & 0.50 & 25.08 & 800 & 43.43 & 1.50 & 8.661 \\
\hline 1200 & 4015.5 & 32.01 & 0.80 & 23.81 & 1200 & 41.24 & 1.04 & 18.48 \\
\hline 1600 & 5064.6 & 67.00 & 1.32 & 52.93 & 1600 & 91.68 & 1.82 & 38.68 \\
\hline
\end{tabular}

${ }^{\mathrm{a}} n=6,{ }^{\mathrm{b}}$ standard error.

TABle 3: Robustness of the method ${ }^{\mathrm{a}}$.

\begin{tabular}{lcl}
\hline \multirow{2}{*}{ Parameter } & $\begin{array}{c}\mathrm{SD}^{\mathrm{b}} \text { of peak } \\
\text { area }\end{array}$ & \% R.S.D. \\
\hline Mobile phase composition & 31.35 & 1.05 \\
Amount of mobile phase & 34.83 & 1.14 \\
Temperature & 38.21 & 1.25 \\
Relative humidity & 36.26 & 1.19 \\
Development distance & 32.28 & 1.07 \\
Time from spotting to chromatography & 32.45 & 1.07 \\
Time from chromatography to scanning & 20.85 & 0.70 \\
\hline
\end{tabular}

${ }^{\mathrm{a}} n=6,{ }^{\mathrm{b}}$ Average of one concentration: $800 \mathrm{ng}$ per spot.

TABLE 4: Recovery studies ${ }^{\mathrm{a}}$.

\begin{tabular}{lcccc}
\hline $\begin{array}{l}\text { Excess drug added } \\
\text { to }^{\text {b }} \text { the analyte }(\%)\end{array}$ & $\begin{array}{c}\text { Amount } \\
\text { recovered } \\
(\mathrm{mg})\end{array}$ & $\begin{array}{c}\text { Recovery } \\
(\%)\end{array}$ & \% R.S.D & S.E. \\
\hline 0 & 809.23 & 101.15 & 0.40 & 4.99 \\
80 & 1447.91 & 99.79 & 0.57 & 12.71 \\
100 & 1613.94 & 100.59 & 0.70 & 17.21 \\
120 & 1629.84 & 101.49 & 0.19 & 4.80 \\
\hline
\end{tabular}

${ }^{\mathrm{a}} n=6,{ }^{\mathrm{b}}$ matrix containing $100 \mathrm{mg}$ drug.

at three different concentration levels of 800,1200 , and 1600 ng per spot.

3.3.2. Robustness of the Method. The standard deviation of peak areas was calculated for each parameter, and the percentage of R.S.D. was found to be less than $2 \%$. The low values of the percentage of R.S.D. values, shown in Table 3, indicated robustness of the method.

3.3.3. $L O D$ and $L O Q$. The calibration curve in this study was plotted between the amount of analyte versus average response (peak area), and the regression equation was obtained $(Y=3.284 X+416.0)$ with a regression coefficient of 0.998. Detection limit and quantification limit were calculated by the method as described in Section 2.3.4 and were found to be 20.49 and $62.10 \mathrm{ng}$, respectively.

3.3.4. Specificity. The peak purity of tamsulosin hydrochloride was assessed by comparing the spectra at peak start, peak apex, and peak end positions of the spot which was obtained between standard and sample spectra of tamsulosin hydrochloride (Figure 7).

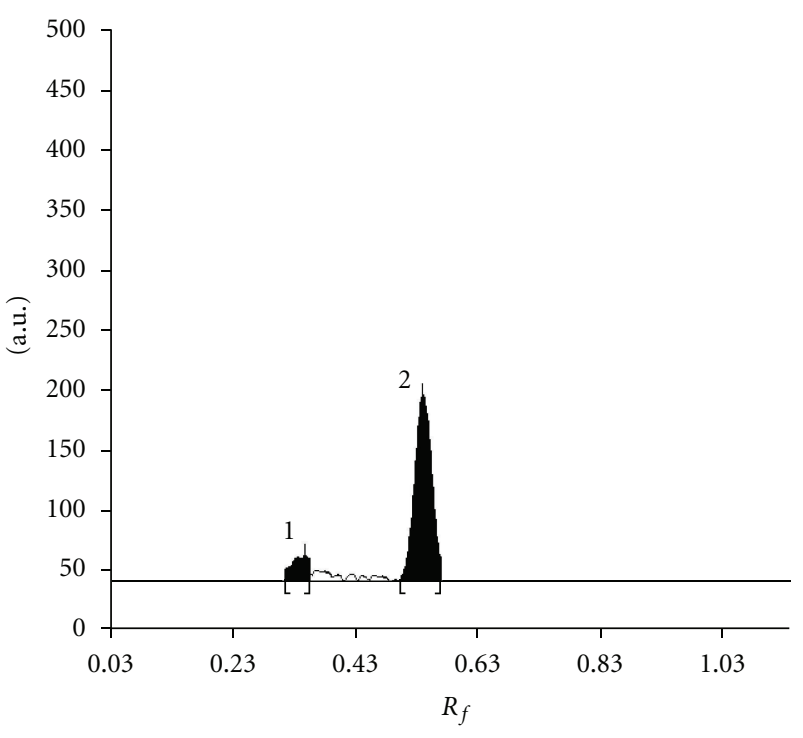

FIgURE 3: HPTLC densitogram of tamsulosin hydrochloride after photo degradation at " $24 \mathrm{~h}$ ” in sun light.

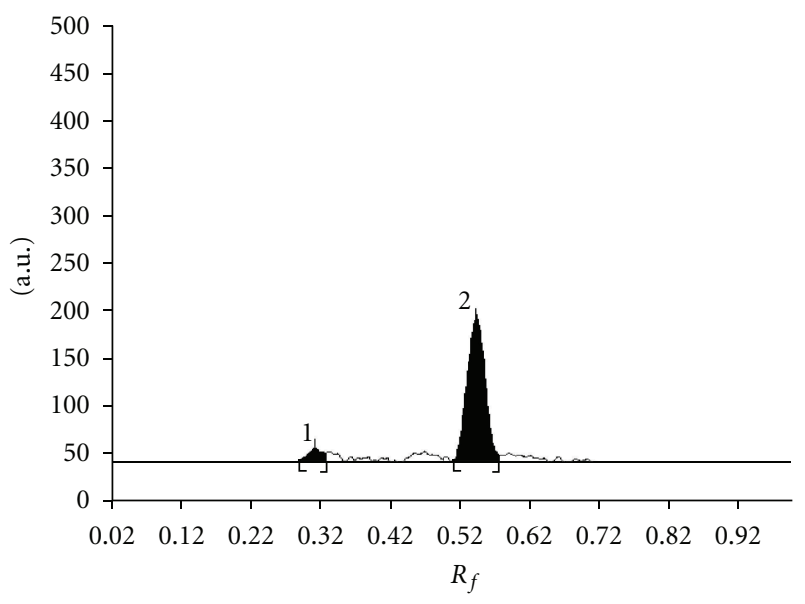

FIGURE 4: HPTLC densitogram of tamsulosin hydrochloride after $\mathrm{HCl}$ degradation for " $8 \mathrm{~h}$ " at room temperature and " $1 \mathrm{~h}$ " reflux.

3.3.5. Recovery Studies. The proposed method, when used for extraction and subsequent estimation of tamsulosin hydrochloride from pharmaceutical dosage forms after spiking with 80,100 , and $120 \%$ of additional drug, afforded recovery of $99.79 \%-101.59 \%$ as listed in Table 4 . The data of summary of validation parameters are listed in Table 1. 
TABLE 5: Forced degradation of tamsulosin hydrochloride.

\begin{tabular}{|c|c|c|c|c|c|}
\hline $\begin{array}{l}\text { Serial } \\
\text { number }\end{array}$ & Sample exposure condition & $\begin{array}{l}\text { Number of degradation } \\
\text { products }\left(R_{f} \text { value }\right)\end{array}$ & $\begin{array}{l}\text { Tamsulosin hydrochloride } \\
\text { remained }(\mathrm{ng} / 1200 \mathrm{ng}) \\
( \pm \text { S.D }, n=3)\end{array}$ & S.E. & $\begin{array}{c}\text { Recovery } \\
(\%)\end{array}$ \\
\hline 1 & $2 \mathrm{~N} \mathrm{HCl}$ " $8 \mathrm{~h}$ " at room temp. reflux for " $1 \mathrm{~h}$ " & $1(0.29)$ & $1055.8(7.90)$ & 1.810 & 87.99 \\
\hline 2 & $2 \mathrm{~N} \mathrm{NaOH}$ " $8 \mathrm{~h}$ ” room temp. reflux for " $1 \mathrm{~h}$ ” & $1(0.26)$ & $983.76(5.01)$ & 2.092 & 81.98 \\
\hline 3 & $30 \% \mathrm{H}_{2} \mathrm{O}_{2} " 16 \mathrm{~h} "$ & $1(0.34)$ & $1020.66(14.00)$ & 2.034 & 85.06 \\
\hline 4 & Heat for " $2 \mathrm{~h}$ " at $60^{\circ} \mathrm{C}$ & $1(0.31)$ & $1028.72(10.10)$ & 2.244 & 85.73 \\
\hline 5 & Photo degradation kept for “ $24 \mathrm{~h}$ ” & $1(0.28)$ & $1069.81(16.81)$ & 0.900 & 89.15 \\
\hline
\end{tabular}

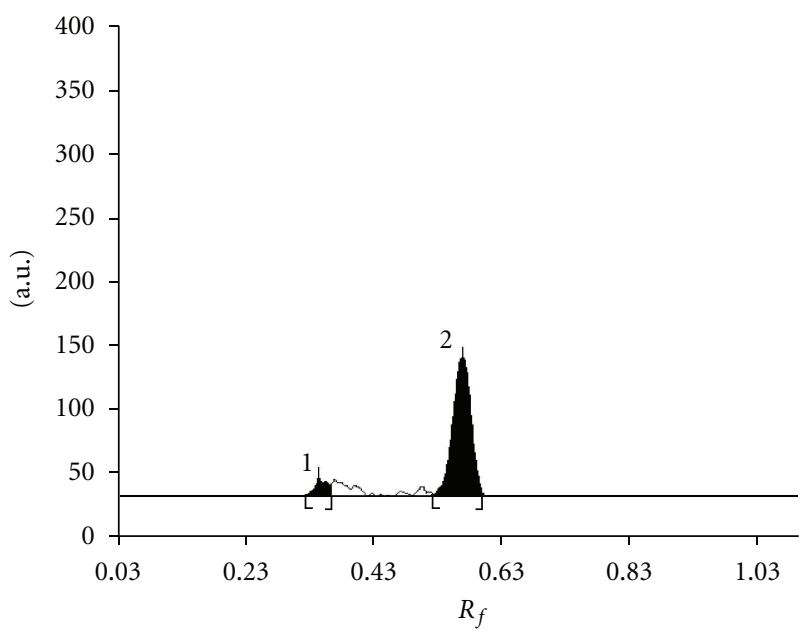

Figure 5: HPTLC densitogram of tamsulosin hydrochloride after $\mathrm{NaOH}$ degradation for " $8 \mathrm{~h}$ " at room temperature and "1-hour" reflux.

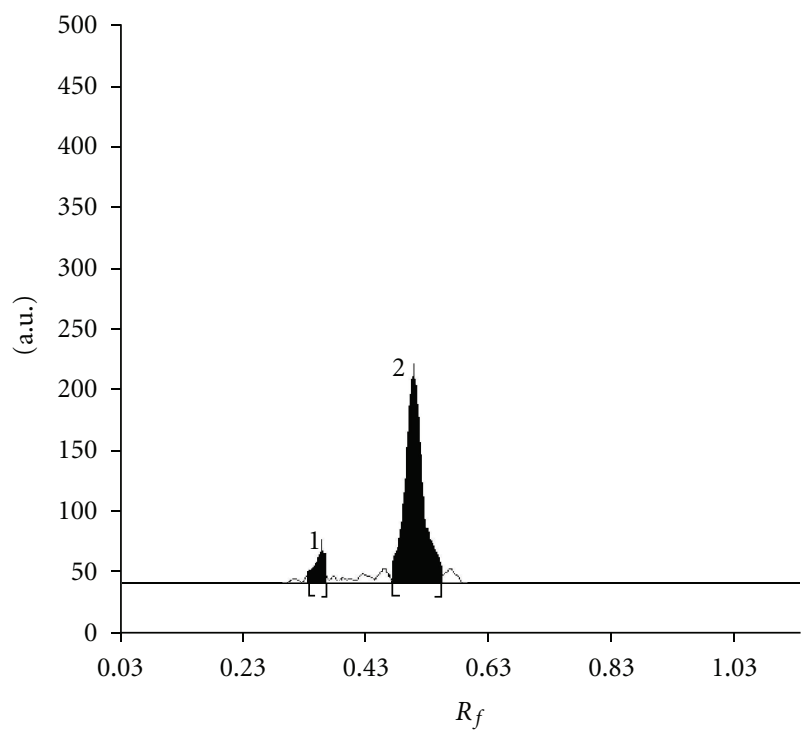

FIGURE 6: HPTLC densitogram of tamsulosin hydrochloride after "2-hour" dry heat degradation at $60^{\circ} \mathrm{C}$.

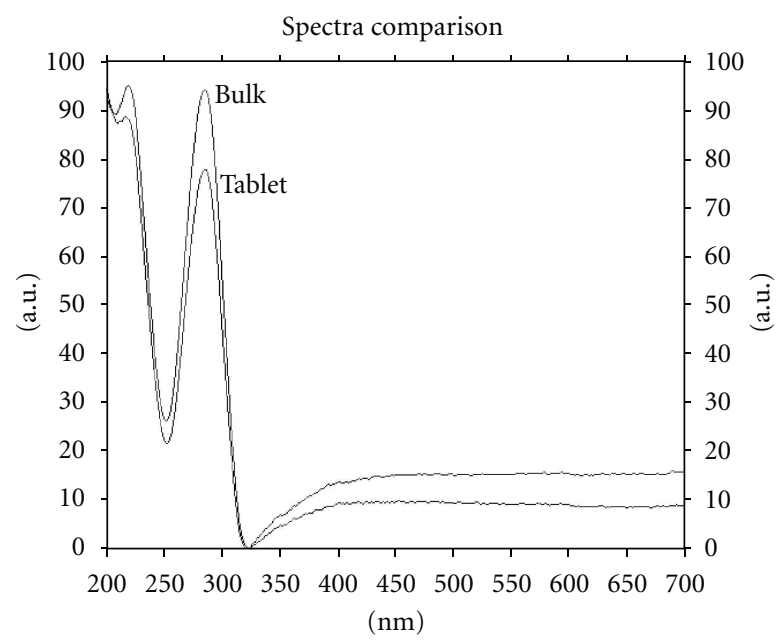

FIGURE 7: Absorption spectra of tamsulosin hydrochloride bulk and tablet formulation.

3.4. Analysis of Prepared Formulation. A single spot of $R_{f}$ 0.52 was observed in chromatogram of the tamsulosin hydrochloride samples extracted from tablet. There was no interference from the excipients commonly present in the tablets. The tamsulosin hydrochloride content was found to be $100.56 \%$ with an R.S.D. percentage of 0.68 . It may, therefore, be inferred that degradation of tamsulosin hydrochloride had not occurred in the formulation that was analysed by this method. The low percentage of R.S.D. value indicated the suitability of this method for routine analysis of tamsulosin hydrochloride in pharmaceutical dosage forms.

3.5. Stability-Indicating Property. The chromatogram of samples degraded with acid, alkaline hydrolysis, hydrogen peroxide, and heat showed well-separated spots of pure tamsulosin hydrochloride as well as some additional peaks at different $R_{f}$ values. The spots of degraded product were well resolved from the drug spot as shown in Figures 2, 3, 4 , and 5. The conditions of degradation, number of degradation products with their $R_{f}$ values, content of tamsulosin hydrochloride determined, and percentage recovery were calculated and listed in Table 5. 


\section{Conclusion}

The developed HPTLC technique is precise, specific, accurate, and stability indicating. The developed method was validated based on ICH guidelines [18-20]. Statistical analysis proves that the method is repeatable and selective for the analysis of tamsulosin hydrochloride as a bulk drug and in pharmaceutical formulations.

The method can be used to determine the purity of the drug available from the various sources by detecting the related impurities. It may be extended to study the degradation kinetics of tamsulosin hydrochloride and for its estimation in plasma and other biological fluids. As the method separates the drug from its degradation products, it can be employed as a stability-indicating one.

\section{References}

[1] Martindale, The Extra Pharmacopoeia, Council of Royal Pharmaceutical Society of Great Britain, 29th edition, 1989.

[2] S. Budavari, The Merck Index, Merck and Co. Inc., White House Station, NJ, USA, 14th edition, 1996.

[3] V. Maier, J. Horáková, J. Petr, E. Tesařová, P. Coufal, and J. Ševčík, "Chiral separation of tamsulosin by capillary electrophoresis," Journal of Pharmaceutical and Biomedical Analysis, vol. 39, no. 3-4, pp. 691-696, 2005.

[4] Z. Zhang, G. Yang, G. Liang, H. Liu, and Y. Chen, "Chiral separation of Tamsulosin isomers by HPLC using cellulose Tris (3,5-dimethhylphenylcarbamate) as a chiral stationary phase," Journal of Pharmaceutical and Biomedical Analysis, vol. 34, no. 3, pp. 689-693, 2004.

[5] V. V. Pande, "Simultaneous estimation of Tamsulosin hydrochloride and Dutasteride in combined dosage form by UV spectroscopy method," Journal of Pharmacy Research, vol. 3, p. 15, 2009.

[6] M.V. Basaveswara Rao, B. C. K. Reddy, T. Srinivas Rao, and G. Venkata Rao, "Drug release method by HPLC for tamsulosin hydrochloride $0.2 \%$ and tolterodine tartrate $0.2 \%$ combination pellets," International Journal of Chemical Engineering Research, vol. 1, no. 2, pp. 155-159, 2009.

[7] D. Patel and N. Patel, "Validated RP-HPLC and TLC methods for simultaneous estimation of tamsulosin hydrochloride and finasteride in combined dosage forms," Acta Pharmaceutica, vol. 60, no. 2, pp. 197-205, 2010.

[8] J. G. Chandorkar, V. B. Kotwal, N. S. Dhande, S. G. Gurav, V. V. Pande, and P. V. Yadav, "A sensitive HPLC method for simultaneous estimation of tamsulosin hydrochloride and its impurity," Pakistan Journal of Pharmaceutical Sciences, vol. 21, no. 3, pp. 307-310, 2008.

[9] R. N. Rao, M. V. N. Kumar Talluri, A. N. Raju, D. D. Shinde, and G. S. Ramanjaneyulu, "Development of a validated RPLC/ESI-MS-MS method for separation, identification and determination of related substances of tamsulosin in bulk drugs and formulations," Journal of Pharmaceutical and Biomedical Analysis, vol. 46, no. 1, pp. 94-103, 2008.

[10] M. Qi, P. Wang, and R. Cong, "Determination of the enantiomers of tamsulosin hydrochloride and its synthetic intermediates by chiral liquid c hromatography," Chromatographia, vol. 59, no. 3-4, pp. 251-254, 2004.

[11] J. G. Chandorkar, V. B. Kotwal, N. S. Dhande, S. G. Gurav, V. V. Pande, and P. V. Yadav, "A sensitive HPLC method for simultaneous estimation of tamsulosin hydrochloride and its impurity," Pakistan Journal of Pharmaceutical Sciences, vol. 21, no. 3, pp. 307-310, 2008.

[12] L. Ding, M. Li, P. Tao, J. Yang, and Z. Zhang, "Quantitation of tamsulosin in human plasma by liquid chromatographyelectrospray ionization mass spectrometry," Journal of Chromatography B, vol. 767, no. 1, pp. 75-81, 2002.

[13] S. Yamada, C. Tanaka, M. Suzuki, T. Ohkura, R. Kimura, and K. Kawabe, "Determination of $\alpha$-adrenoceptor antagonists in plasma by radioreceptor assay," Journal of Pharmaceutical and Biomedical Analysis, vol. 14, no. 3, pp. 289-294, 1996.

[14] K. Hanada, N. Tochikura, and H. Ogata, "Selective binding of tamsulosin to genetic variants of human $\alpha$-acid glycoprotein," Biological and Pharmaceutical Bulletin, vol. 30, no. 8, pp. 15931595, 2007.

[15] P. Keski-Rahkonen, O. Pärssinen, E. Leppänen, T. Mauriala, M. Lehtonen, and S. Auriola, "Determination of tamsulosin in human aqueous humor and serum by liquid chromatographyelectrospray ionization tandem mass spectrometry," Journal of Pharmaceutical and Biomedical Analysis, vol. 43, no. 2, pp. 606-612, 2007.

[16] N. V. S. Ramakrishna, K. N. Vishwottam, S. Manoj, M. Koteshwara, S. Wishu, and D. P. Varma, "Rapid, simple and highly sensitive LC-ESI-MS/MS method for the quantification of tamsulosin in human plasma," Biomedical Chromatography, vol. 19, no. 10, pp. 709-719, 2005.

[17] M. Bakshi and S. Singh, "Development of validated stabilityindicating assay methods_critical review," Journal of Pharmaceutical and Biomedical Analysis, vol. 28, no. 6, pp. 1011-1040, 2002.

[18] ICH Q2A Guideline, Validation of Analytical Procedures: Definition and Terminology (CPMP III/ 5626/94), ICH, Geneva, Switzerland, 1995.

[19] ICH-Guidelines Q2B, Validation of Analytical Procedures: Methodology (CPMP/ICH/281/95), ICH, Geneva, Switzerland, 1996.

[20] ICH-Guidelines Q1A- Q1E, Stability Testing of New Drug Substances and Products, 2003. 


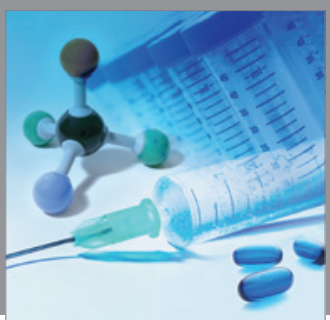

International Journal of

Medicinal Chemistry

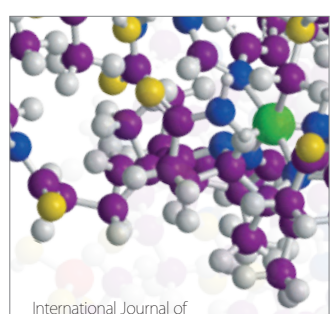

Carbohydrate Chemistry

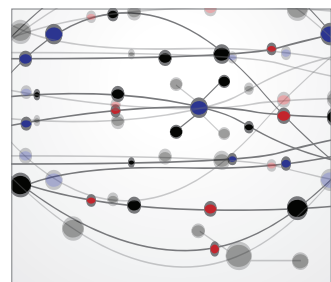

The Scientific World Journal
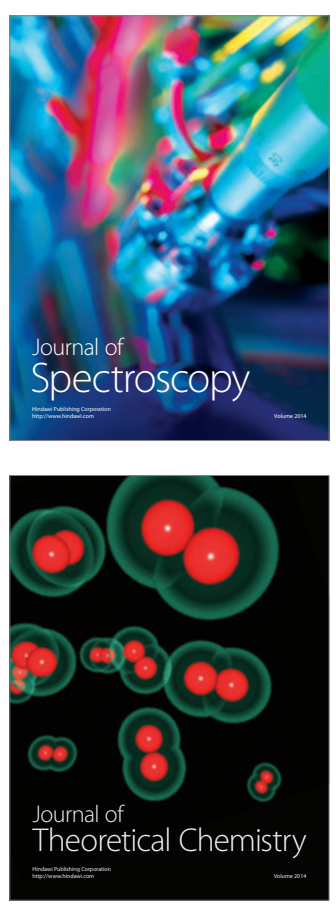
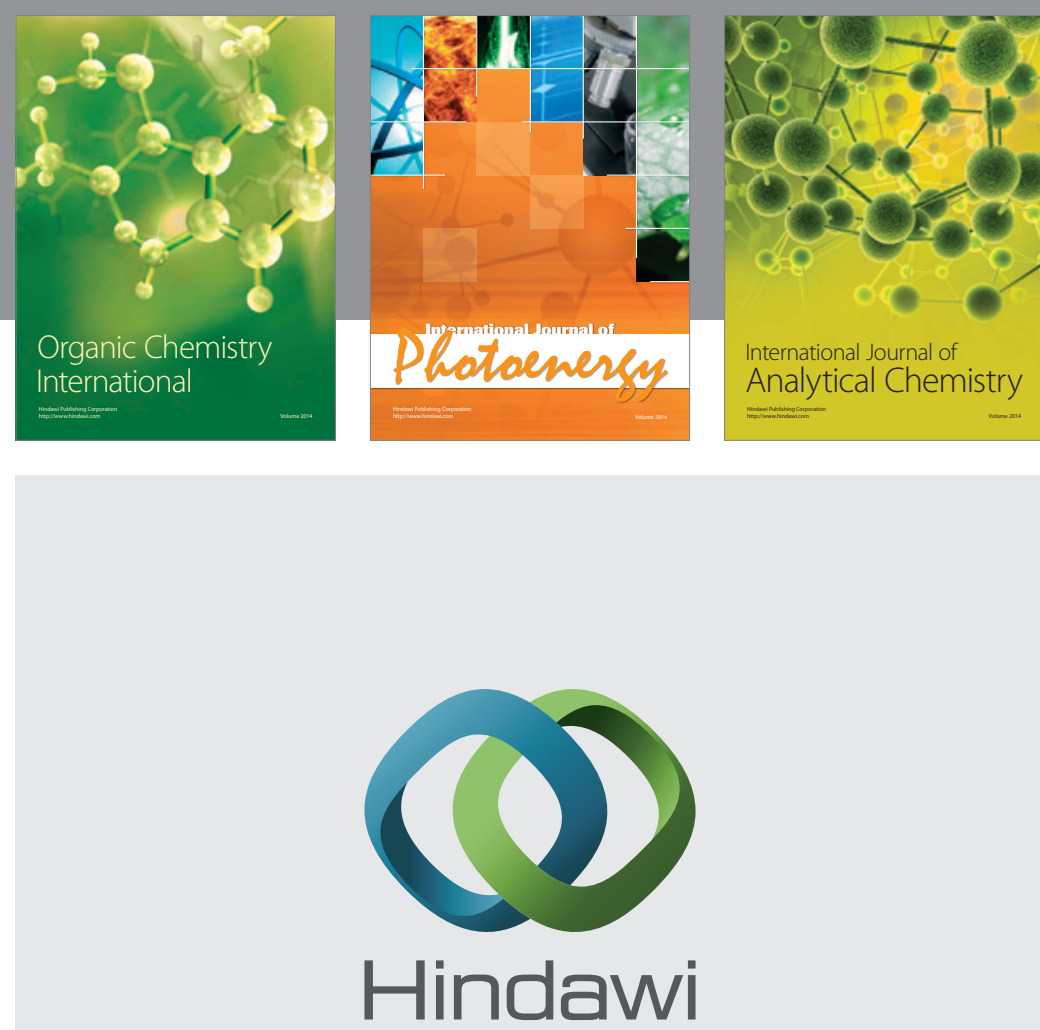

Submit your manuscripts at

http://www.hindawi.com
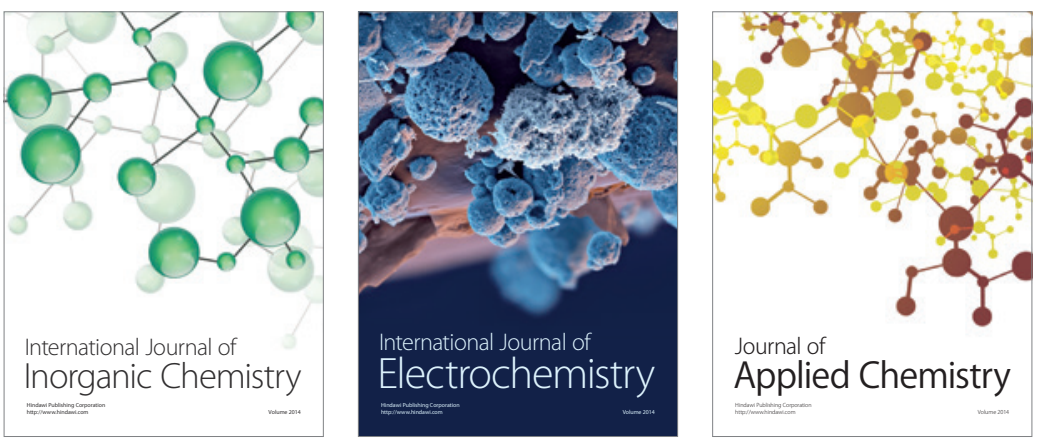

Journal of

Applied Chemistry
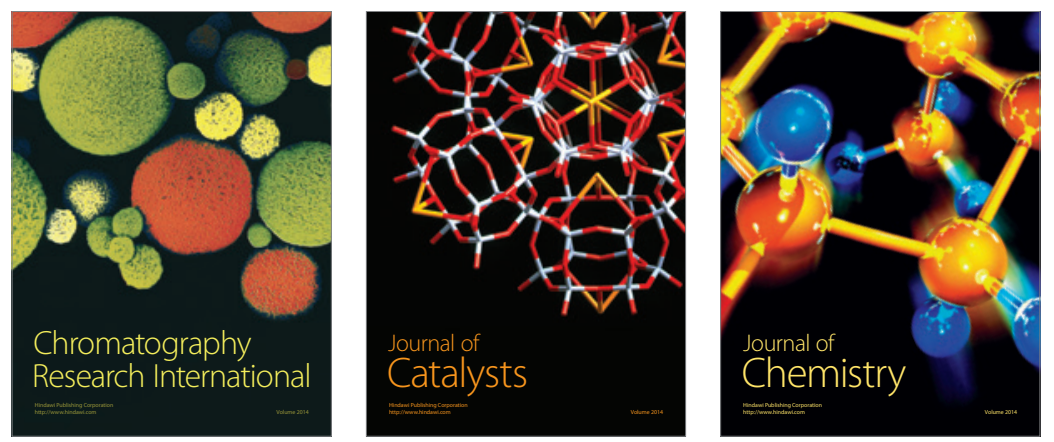
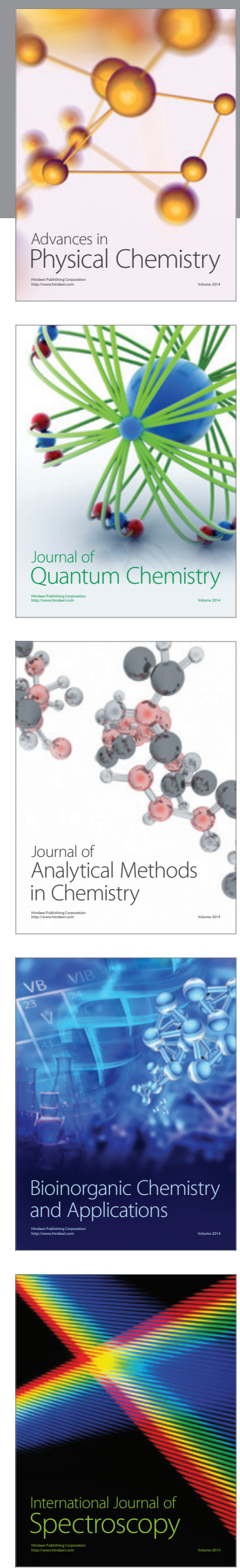